\title{
Sewage Water as Resources for Green Energy by using Hydro Turbines, Pumped Energy Storage, Waste and Bio Systems
}

\author{
Rafi Glick \\ Ben Gurion University of the Negev, \\ Beer Sheba, Israel \\ Rafi.glick@gmail.com
}

\section{Extended Abstract}

This project is about "Ecological Treatment of Waste water and how to Turn Nuisance into a Resources.

Regional Cross Border Pollution need Cross Border relation and could create potential risks and opportunities. Some 16 streams in Israel are transboundary in nature shared between Israel and the Palestinian Authority, with roughly two-thirds originating in Palestinian territory, moving across Israel and emptying into the Mediterranean Sea to the west. The difficulties in Israeli-Palestinian cooperation result in persistently high levels of pollution in the environmental conditions of these waterways.

The project implements solutions for the utilization of wastewater and the differences of 301 meters in elevation between the Hebron heights and Beer Sheba regions, as sources for the production of green energy, including electricity generation using hydroelectric systems, Pumped Energy Storage and the generation of electricity through bio-gas and waste incineration.

Due to environmental risks in the regions we proposed an optimal unilateral economics and environmental activities by the Israeli authorities when sharing in resources and expenses will be delayed to time to come and the findings and the contribution is as follows.

1. The contribution from energy production will enable reduction of pollution and diverting tens of millions of cubic meters of purified water and flood water to agricultural development and tourism uses.

2. The realization of the project for the treatment of the Meitar Basin wastewater is expected to contribute greatly to Israel in general and the Negev in particular. Alongside the ecological and environmental contribution of the project, in view of the danger facing the groundwater, its contribution to the development of the Negev is reflected in the social and economic-occupational aspects.

3. According to the implementation plan mentioned above, it can be seen that the use of renewable energies will generate future profits. In addition, tens of millions of cubic meters of sewage that today pollute the Negev and the aquifer have been reused for agricultural use, as well as some of the floodwater polluted by the sewage water and are now inoperable.

4. The clean water flowing into the stream will contribute greatly to the development of tourism in the area (as planned in the Beer Sheba River Rehabilitation Project), which may directly affect the prosperity of the Negev region economy.

5. Implementation of the project may lead to increased employment in tourism and agriculture and the creation of new jobs following the expansion of infrastructure.

6. Purification of the drainage basin will also increase existing grazing areas and prevent animal mortality, which is an important source of income for the residents of the area.

7. The total investment in the gross project (including all sub projects) will be around 23,6 M\$ and the breakeven point is expected after four years.

\section{References}

[1] Clive Lipchin, Shira Kronich, Jaclyn Best, "Wastewater in the West Bank - Report for the Knesset," Centre for Transboundary Water Management, Arava Institute for Environmental Studies, February 7th 2016.

[2] B. J. M. De Vries, Sustainability Science. Cambridge University Press, pp. 392-397, 2013.

[3] Robertson Margaret, Sustainability Principles and Practice. New York, pp. 3, 2014. 